\title{
Social Learning and Scaffolding to Improve Student's Self-efficacy and Engagement
}

\author{
Muztaba Fuad \\ Computer Science \\ Winston-Salem State University \\ Winston-Salem, NC \\ fuadmo@wssu.edu
}

\author{
Monika Akbar \\ Computer Science \\ University of Texas at El-Paso \\ El-Paso, TX \\ makbar@utep.edu
}

\author{
Lynn Zubov \\ Education \\ Winston-Salem State University \\ Winston-Salem, NC \\ zubovl@wssu.edu
}

\begin{abstract}
The majority of Computer Science courses frequently use out-ofclass activities to promote skill-building. Yet, the shortcomings of these activities limit their applicability in improving students' skills. This poster presents an innovative mobile-app-based approach to engage students in out-of-class activities. The app Dysgu - builds on the theories of social learning and enables instructors to break regular out-of-class activities into smaller and interactive entities with instructional scaffolding. Dysgu allows students to compare their progress with their peers and provides personalized notifications and feedbacks to keep students engaged. The goal is to improve student's self-efficacy and engagement in out-of-class activities.
\end{abstract}

\section{CCS CONCEPTS}

- Social \& professional topics Computing education • Applied computing $\sim$ Computer-managed instruction

\section{KEYWORDS}

Mobile learning, instructional scaffolding, homework.

\section{The Problem}

Traditional out-of-class activities, including assignments, essays, and labs tend to be large in size and scope, and require longer for students to finish and faculty to grade. Because of that, these activities fail to consistently engage students; as a result, many students procrastinate and submit sub-standard work. because of having longer timeframes, faculty assigns a few of these during the semester, minimizing the activity's intended effectiveness.

\section{Significance of this work}

According to the social learning theory, learning is a reciprocal experience where learners take an active role in their learning. Social learning theory suggests that knowledge can be derived from social surroundings through observation, imitation, and modeling. However, observation itself is not sufficient to ensure learning and several factors, including attention, motivation, and

Permission to make digital or hard copies of part or all of this work for personal or classroom use is granted without fee provided that copies are not made or distributed for profit or commercial advantage and that copies bear this notice and the full citation on the first page. Copyrights for third-party components of this work must be honored. For all other uses, contact the Owner/Author.

SIGCSE '20, March 11-14, 2020, Portland, OR, USA

(c) 2020 Copyright is held by the owner/author(s).

ACM ISBN 978-1-4503-6793-6/20/03.

https://doi.org/10.1145/3328778.3372583 self-efficacy, should be considered for a successful social learning experience. With traditional out-of-class activities, students are unaware of the class's progress, and how a student is performing compared to the rest of the class. Only after an activity is graded, students can receive information on the class's performance through the learning management system's limited statistical indicators. This might have negative effects on a student's submission attitude, time-management, and standards of submission. This research builds upon the hypothesis that if students can compare their progress in real-time with the rest of the class, it will promote their self-fulfilling prophecy [1].

\section{Approach Overview}

Through Dysgu [2], this research aims to improve student's participation and engagement in out-of-class activities. Dysgu enables instructors to redesign the out-of-class activities to be smaller in scope and interactive in nature. Dysgu allows arranging questions into learning paths with instructional scaffolding. Students can compare their progress (statistical, summative, etc.) with the rest of the class. Moreover, Dysgu reminds and alerts students of their status as the class continues to progress along the different learning paths. Some activities act as practice without any score, while other act as extra credit and allow students to gather points. These points can be used as currency to extend deadlines or buy hints. Students can set up their schedules and privacy features to make Dysgu adaptive to their needs.

\section{Initial Results and Future Work}

The initial usability test shows that students demonstrate highly positive attitudes towards Dysgu, specifically at the interactivity, prompt feedback, notification and personalization features, and the comparisons of one's progress with the rest of the class. Dysgu is slated to be used in two freshmen courses in two different universities starting Spring 2020. Future work includes support for adaptive learning paths.

\section{ACKNOWLEDGMENTS}

This research is supported by NSF \# 1712030 and 1712073.

\section{REFERENCES}

[1] Blose, G. (1999). Modeled Retention and Graduation Rates: Calculating Expected Retention and Graduation Rates for Multi campus University Systems. New directions for higher education, 108, 69-86.

[2] Fuad, M., Akbar, M., \& Zubov, L.. Dysgu: A Mobile-Based Adaptive System to Redesign Out-of-class Activities. In 2018 IEEE Frontiers in Education Conference (FIE) (pp. 1-5). IEEE. 